\title{
Review on Tablet in Tablet techniques
}

\author{
Sachin S. Gaikwad ${ }^{*}$ and Sanjay J. Kshirsagar
}

\begin{abstract}
Background: Among all available dosage form, tablet is most widely used because of its stability and patient acceptability. The better aesthetic quality like color, texture, mouth feel, and taste masking depended on film and sugar coatings, so the coating is an important part in the formulation of the tablet. The present work aims to comprehensively review the formulation, characterization, and challenges in the development of Tablet in Tablet dosage form.

Main text: Film and sugar coatings have the number of disadvantages; most important one is the utilization of aqueous or organic solvent that leads to toxicity. To overcome this problem in the year 1896, Noyes firstly introduced the compression coating or Tablet in Tablet technique. In the development of Tablet in Tablet dosage form, substantial attention among researchers and various research reports and patents inputs can be found in the literature. Also, we focused on the recent advancements in techniques like one-step dry-coating (OSDrC ${ }^{\oplus}$ ) for manufacturing Tablet in Tablet dosage form.

Conclusion: The current review gathered information on the latest patent, formulation, advantages, and disadvantages of Tablet in Tablet or compression coating. The review also elaborates on the importance of Tablet in Tablet techniques in the development of a modified release system.
\end{abstract}

Keywords: Tablet in Tablet, OSDrC ${ }^{\oplus}$, Patent, Drug release

\section{Background}

Tablet is the most widely used dosage form among the total available dosage forms because it is simple for administration, lower price of production, and elegance [13]. The aesthetic quality like color, texture, mouth feels, and taste masking is depending on coating techniques. This coating technology having certain limitation or drawbacks to overcome this limitation Tablet in Tablet is one of the best alternatives. The present work aims to comprehensively review the formulation, characterization, and challenges in the development of Tablet in Tablet dosage form. Currently a very less number of patents are filed or granted on this topic; it includes the patent on the Tablet in Tablet of cyclophosphamide and capecitabine, and here, we focused on the rationale behind the development of such dosage form. In this review, we try to highlight the advancement in the manufacturing process of Tablet in Tablet and also explain how it is beneficial for pharmaceutical industry.

\footnotetext{
* Correspondence: sachingaikwad619@gmail.com

Department of Pharmaceutics, MET's Institute of Pharmacy, Affiliated to

Savitribai Phule Pune University, Bhujbal Knowledge City, Adgaon, Nashik 422003, India
}

\section{Main text}

The coating also gives physical and chemical protection to the drug; apart from this, it will also modify the release behavior of the drug. In the nineteenth century, to mask the bitter taste, modern pharmaceutical coating i.e. sugar coating was applied. Sugar coating having certain drawbacks or limitations; it has required long processing time up to 6 to 7 days; it required multistep operation (sealing, subcoating, smoothing, coloring, polishing, etc.) for that skilled operator required. It also has problems like coating process without automation, weight gaining, and sugar solution susceptible to bacterial growth which led to discovery of other coating techniques. The processing time required in sugar coating was majorly reduced in film coating. In 1954, Abbott Laboratories was launched first film-coated tablet in the market. In coating technology, the film coating makes the fastest revolution; it offers batch-tobatch consistency in the formulation development; it can be applied for different dosage forms, and easy process control and process automation is possible. The aqueous- and organic-based polymeric solutions were easily used in the process of film coatings, but both of these polymeric solutions have their disadvantage. The organic solvents used for film coating have some drawbacks of flammability and 
toxicity, residual solvents in film, and the cost of organic solvent. In the case of aqueous film coating, heat requirement and prolong drying period well increase the total manufacturing cost and are a major disadvantage [2].

The compression coating technique was firstly introduced by Noyes in an 1896 patent. In the development of a new drug delivery system, the compression coating is one of the best alternatives, a novel coating technology. It has been used for a different purpose in the pharmaceutical such as the development of modified release, pulsatile release, colon-specific release, and programmable release. According to the various available literature, the press coating technology is used for the development of tablet like as compress coating tablets, e.g., development of glipizide tablet which is designed to achieve zero-order release [6].

To overcome the trouble of film or sugar coating, Tablet in Tablet or compress coating introduces as alternating coating technique. It is also recognized as a dry coating or press coating and was one of the first solvent free-coating techniques. In general, a Tablet in Tablet or compression-coated tablet consists of two parts; one is an internal drug core, and another is an outside coating shell. The outer layer surrounds the inner core, and it mainly controls the strength of the film coating, the release of the drug, and the stability [15].

\subsection{Advantages of Tablet in Tablet technology $[2,9]$}

- Separation of incompatible material can be achieved in the core and outer shell.

- It will use to develop a modified release product (e.g., delayed release product)

- The Tablet in Tablet of two different drugs can be targeted in two different areas of the gastrointestinal tract.

- The need for a separate coating process of the tablets can be avoided in the press coating of the core and coating layer.

- It is a solventless coating, so it is not hazardous to the environment.

- The pharmacokinetic interaction (drug-drug) between concomitantly administered medications can be avoided in Tablet in Tablet dosage form by creating the time interval in their release.

- The Tablet in Tablet dosage form gives protection to the hygroscopic or thermo-liable drug.

- In single Tablet in Tablet dosage form, immediate release and sustain release effect of a similar drug or different drug combination can be achieved.

\subsection{Challenges related to Tablet in Tablet technology}

- The cross contamination possibility between the layers.
- Between the adjacent layers, the elastic modulus is a mismatch. There are an inadequate layer attachment and relatively low interfacial strength because of the high elastic modulus ratio between neighboring layers.

- Face challenges for long term retaining physical and chemical integrity of device during its storage.

- Due to the large tablet size, it creates a swallowing problem [1].

- The difference in coating performance when the core tablet is not located in the center of the system [2].

\subsection{Patent review}

\subsubsection{Tablet in Tablet of cyclophosphamide and capecitabine}

Cyclophosphamide is a prodrug that is converted into its active form when it passes through liver; its active form only is responsible for slowdowns the growth of cancer cells. The treatments of various cancers like metastatic breast cancer, ovarian cancer, and leukemia cyclophosphamide used alone or in combination. Capecitabine is another drug that is also used for the treatment of metastatic breast cancer. Also, the combination partner of capecitabine plays an important role in the activation of thymidine phosphorylase (TP) enzyme, which converts capecitabine to active 5-FU (fluorouracil).

The oral administration of cyclophosphamide and capecitabine may have a better potential for the management of metastatic breast cancer; it was observed by many clinicians. The total impurity level was found to have increased drastically when these two therapeutic agents are used in combination; it is only because of incompatibility between two therapeutic agents, so the development of stable oral composition of these drugs was somewhat difficult. Cyclophosphamide undergoes hydrolysis and easily degraded in presence of aqueous solution and light. It is also labile to high temperature [12].

In this case study, the above problem can be overcome by the development of Tablet in Tablet (US 20190142755) single-unit stable oral dosage form.

\subsection{Tablet in Tablet manufacturing process}

Among all the available dosage forms, tablet is the most popular and convenient solid oral dosage form. Tablets are classified into various types; in one class of tablet, preparations are modified release dosage form that has added significance in drug therapeutics because it offers a variety of advantages. Nowadays, to develop modified released products, the Tablet in Tablet technology (Fig. 1) is the best alternative for bilayer tablet formulation for the incompatible drug. It involves the compression of granular materials around a preformed tablet core using specially designed tableting equipment. The Tablet in Tablet is also 
Outer tablet or shel

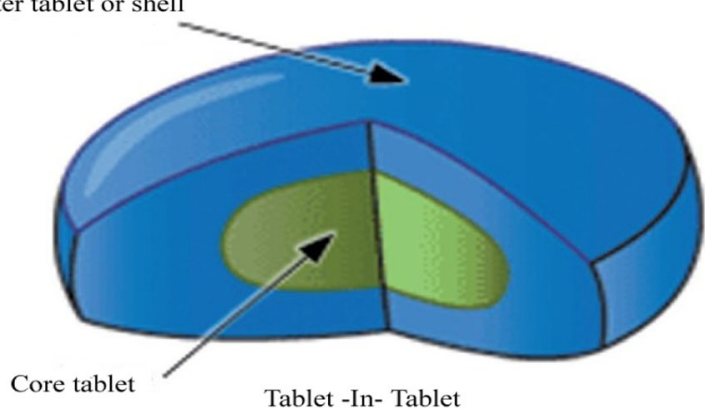

Fig. 1 Tablet in Tablet

known as compression coating or solvent-free-coating technique.

The internal core and outer layer are the two parts of the Tablet in Tablet dosage form. The internal core is a small tablet and prepared by using a somewhat small size of tooling than tooling used for the preparation of the outer coat. After internal tablet core was produced, it is placed (centrally positioned) to another die which is moderately occupied with coating powder and which is larger than core tablet then the remaining amount of coating powder is placed on the top of core tablet and compressed resulting in the formation of tablet within tablet [6]. This process leads to a problem like during the transfer of the core tablet into another die, it may be tilted. To achieve an immediate release product, generally the coat is water soluble and disintegrates easily after oral administration. The Tablet in Tablet can be utilized for the development of repeat action tablets in such a way that initially the external layer releases the initial dose of the drug while the inner core releases later on. The repeat action Tablet in Tablet dosage form showing the risk of overdose toxicity because when the core tablet has rapidly discharged the drug which is completely attained dissimilar blood levels. List of drug formulated in Tablet in Tablet or the compressed coated tablet is shown in Table 1.

Hariharan and Gupta [4] have also reported another method for manufacturing of Tablet in Tablet or compress coated tablet. In this method, there is no need for the formation of the core separately. The modified three layer tablet machine was designed in such a way that core and coated tablet produce simultaneously. The formation of the core tablet takes place on one side of the press, and then, it is shifted to the other side for coating. In this coating process, firstly a cup-shaped outer layer of a coating blend is formed and then entrapment of core material and finally another outer coating layer on the top. The core may consist of pure drug crystals, drug-excipient mixture, granules, microspheres, or beads [2].
Lin et al. [18] reported the application of IR spectrophotometric hydraulic press for the manufacturing of Tablet in Tablet. This press is not suitable for large scale tablet production. The author explains the manual procedure required to produce a dry coated tablet. In that firstly filling of coating powder in die then put core tablet in their center after that apply the compression force. During the dissolution lag time ranging from 1 to $20 \mathrm{hrs}$, it depends on the thickness and particle size of coating powder. Prolong lag time can be achieved with smaller particles [2].

\subsubsection{Recent advancement}

Conventional dry-coating or Tablet in Tablet manufacturing methods depicted as above can create problems, like non-core, double-core, off-center, and inlay, caused by the core tablet transport system. Hence, dry coating or Tablet in Tablet is not as widely used as conventional tablets. The compression of the core tablet in advance is the primary requirement in the abovementioned method (depicted in section 2.4), so it will increase the overall manufacturing cost of the dosage form. To resolve the problems related to the manufacturing of conventional dry-coating methods or Tablet in Tablet formation, new one-step dry-coating $\left(\mathrm{OSDrC}^{\circ}\right)$ equipment was introduced and has brought revolution in tablet manufacturing. The $\mathrm{OSDrC}^{\circ}$ is a registered trademark of Sanwa Kagaku Kenkyusho Co., Ltd., Japan. With this technique, by changing the thickness of outer coating layer formulation, scientist made control over drug release [7].

Firstly the space made by lower center punch and lower outer punch is filled with outer coating layer powder, and then, it is precompressed by the upper center punch. Then, while the upper-center punch pushes the pre-compressed first-outer layer, the lower-center punch is slid down. The upper-center punch is then pulled away to make a space, which is filled with the powder for the core. This is then pre-compressed by the upper-center punch. Finally, the lower-outer punch is slid downward, and the powder for the second-outer layer fills and surrounds the pre-compressed core/first-outer layer. The core/first-outer layer and the second-outer layer complex are then compressed by the upper and lower punches, in which the center punches are unified with the outer punches, respectively [11]. The mechanism of OSDrC manufacturing method is described in Fig. 2.

\subsubsection{Advantages of $\mathrm{OSDrC}^{\circledR}[7]$.}

- This technology will control the weight of the different layer of the tablet because it having single step operation means tablet and core produce in one rotation of the punches on the turntable. It making precise coatings of closely any thickness and tablet 
Table 1 List of drug formulated in Tablet-in-Tablet or compressed-coated tablet

\begin{tabular}{|c|c|c|c|}
\hline Active ingredient & Category/use & Excipients & References \\
\hline Paliperidone & Antipsychotic & HPC-H, Euragit RL-PO, Glycerylbehenate, MCC, HPMC-K100 M & [15] \\
\hline Orlistat and venlafaxine & Antiobesity and antidepressant & $\begin{array}{l}\text { For core tablet- } \beta C D \text {, SD Mannitol, Ludiflash, Kollidon CLF, } \\
\text { Kollidon-30, SLS, Sucrose, Talc, Mg-Stearate, Cherry Flavour, } \\
\text { Methyl Paraben } \\
\text { For outer coating- } \beta C D \text {, Eudragit EPO, Ludipress LCE, } \\
\text { Maltodextrin, Xanthan Gum, Kollidon-30,Citric Acid,Sucralose, } \\
\text { Peppermint flavor, Propyl Paraben, Talc, Mg.Sterate }\end{array}$ & [9] \\
\hline $\begin{array}{l}\text { Amoxicillin and potassium } \\
\text { clavulanate }\end{array}$ & Antibacterial and $\beta$ lactamase inhibitors & Steric acid and avicel layer & [17] \\
\hline Acetaminophen & Analgesic and antipyretic & HPMC, Mg.Sterate, Lactose-crystal cellulose & [11] \\
\hline Glipizide & Antidiabetic & $\beta C D, H P C-L, H P C-M, M C C$, Eudragit RL PO, Mg.Sterate & [5] \\
\hline Nifedipine & Antihypertensive, calcium channel blockers & HPC-L, HPC-M, Eudragit RSPO, Mg.Sterate & [6] \\
\hline Prednisolone & Immuno-suppressant & $\begin{array}{l}\text { Carboxymethyl xanthan gum, Sodium alginate, Calcium } \\
\text { chloride, MCC,Polyplasdone XL, Tri-Sodium Citrate, Trisodium } \\
\text { orthophosphate dodecahydrate, Mg.Sterate. }\end{array}$ & [8]. \\
\hline Carvedilol & $\begin{array}{l}\text { Antihypertensive or non-selective } \\
\text { beta adrenergic receptor blocker }\end{array}$ & $\begin{array}{l}\text { Polyoxy Ethylene Oxide WSR 205, HPMC K KM, MCC, Sodium } \\
\text { starch glycollate, Mg.Sterate. }\end{array}$ & [14] \\
\hline
\end{tabular}
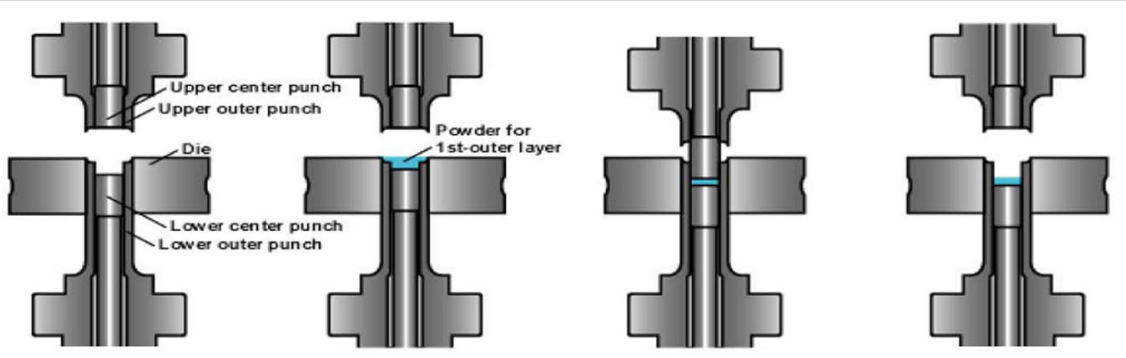

STEP 1

STEP 2

STEP 3

STEP 4
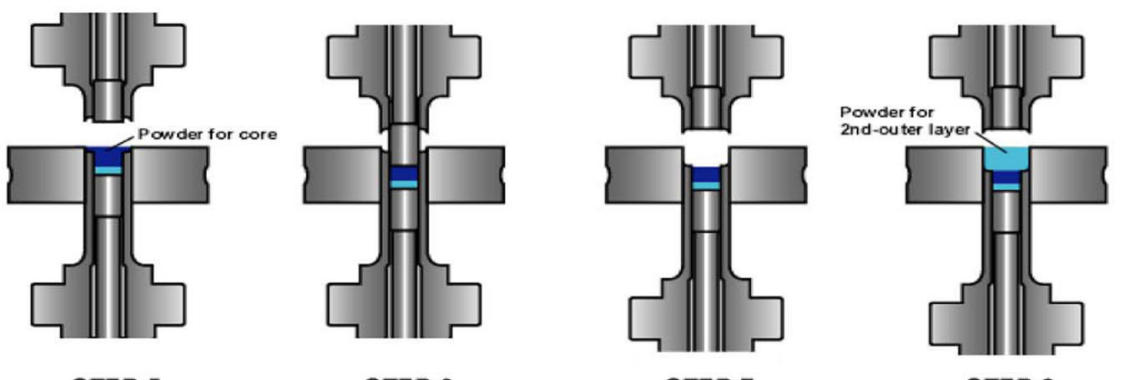

STEP 5

STEP 6
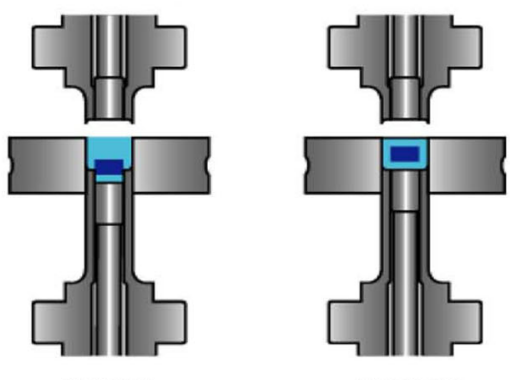

STEP 10
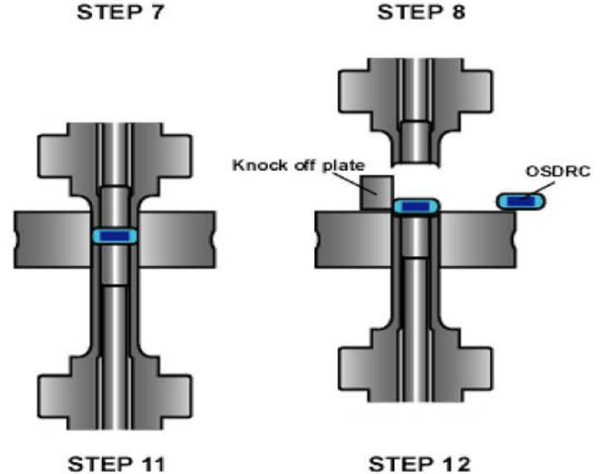

STEP 9

[11]

Fig. 2 Steps of $\mathrm{OSDrC}^{\circledR}$ manufacturing method [11] 
shape by using the advanced cam movement design and adjustable double punch arrangement.

- There is no need for a separate operation to produce a core tablet. It is a single, solvent-freecoating process.

- It gives precision quality tablet due to the design of independently moving variable double punch.

- The modified release formulation or drug delivery can be developed by utilizing this $\mathrm{OSDrC}^{\ominus}$ technology.

\subsection{Characterization of Tablet in Tablet}

\subsubsection{Measurement of radial tensile strength}

With the help of tablet hardness tester (Toyama Kagaku; $\mathrm{TH}-203)$, the radial tensile strength of randomly selected tablets can be measured. Before performing, test tablets are kept in a desiccator for a period of $24 \mathrm{hrs}$. With the help of plunger applying a diametrical load on the tablet and then measure the maximum load $H$ at which tablet gets fractured. Using the following equation, the radial tensile strength calculates $(T)$ [10].

$$
T=\frac{2 H}{\pi d L}
$$

where $d$ is the tablet diameter, and $L$ is the tablet thickness.

\subsubsection{Friability test}

This is the official method to determine the mechanical strength of the tablet. Weight the randomly selected tablet samples as per the USP [16] and put into friabilator (Electrolabo; EF-1 W) plastic drum along with twenty polystyrene beads (Wako Pure Chemical; diameter of $6 \mathrm{~mm}$ ) [10]. Then rotates the drum at $25 \mathrm{rpm}$ up to $4 \mathrm{~min}$ then weigh the tablet again to determine the loss of tablet weight. The percent friability determine by using the following formula [3].

$$
F=\frac{1-W}{W_{0}} \times 100
$$

where, $W_{O}=$ Weight of the tablet before friability.

$$
W=\text { Weight of the tablet after friability }
$$

\subsubsection{Measurement of internal intensity}

The constant load-bearing intensity tester was used for measurement of the internal intensity of the tablet. During the boring of tablet how much penetration of drill tip takes place was measured. The load on the drill is $150 \mathrm{~g}$, and the rotation speed is $200 \mathrm{rpm}$. The relative intensity of the inside of the tablet was evaluated from the boring speed [10].

\subsubsection{In vitro release study}

The USP type-I or type-II apparatus were used for in vitro dissolution study as per the official monograph of the model drug. The dissolution solvent or medium was $900 \mathrm{ml}$ of respective $\mathrm{pH}$ mentioned in the assay of a model drug. Maintaining the temperature $37 \pm 0.5^{\circ} \mathrm{C}$, the rotational speed of the basket or paddle as per official monograph. Samples were withdrawn at a specific interval and replace with the same volume of fresh dissolution solvent then all the samples filtered through a $0.45-\mu \mathrm{m}$ membrane filter and analyzed by UV (Ultra Violet) spectrophotometry at a respective wavelength of the model drug. The drug release studies were performed six times in parallel for each formulation tested, and standard deviations were calculated [6]. This is a general condition but for each drug, you should follow the pharmacopoeia or reference.

\subsubsection{Release mechanism}

Three different stages took place during the releasing of the drug from Tablet in Tablet dosage form, which is shown in Fig. 3. In the first stage, there is penetration of the dissolution medium into the tablet leads to swelling of the coating layer. In the second stage, rapid penetration of dissolution medium through the outer layer produces the erosion of the outer coating barrier. Due to the swelling of the inner tablet or core tablet increase, the pressure leads to the rupture of the coating layer. In the third stage after a lag time, the dissolution corresponding to a quick drug release of the core tablet takes place.

\subsubsection{Erosion and absorption studies}

In the development of modified release formulation in the form of Tablet in Tablet that time erosion and absorption studies are carried out with gravimetric analysis by utilizing the USP type-II dissolution apparatus. The tablets were placed in the basket (rotation speed is $100 \mathrm{rpm}$ ) and are immersed in a 900-ml buffer solution ( $\mathrm{pH}$ as per official monograph of the model drug) at $37 \pm 0.5^{\circ} \mathrm{C}$. At different time points, tablets were removed from the dissolution medium and remove excess surface water carefully using filter paper and weighed. The tablets were then dried in a hot air oven at $60^{\circ} \mathrm{C}$ till a constant weight was reached, and at each time, point six different tablets were measured. At each time point, a fresh or new tablet was used. The remaining mass (RM) is measured as erosion. The water uptake and expansion process were explained by the swelling ratio (SR). The RM and SR were calculated using the following formula [6]. 


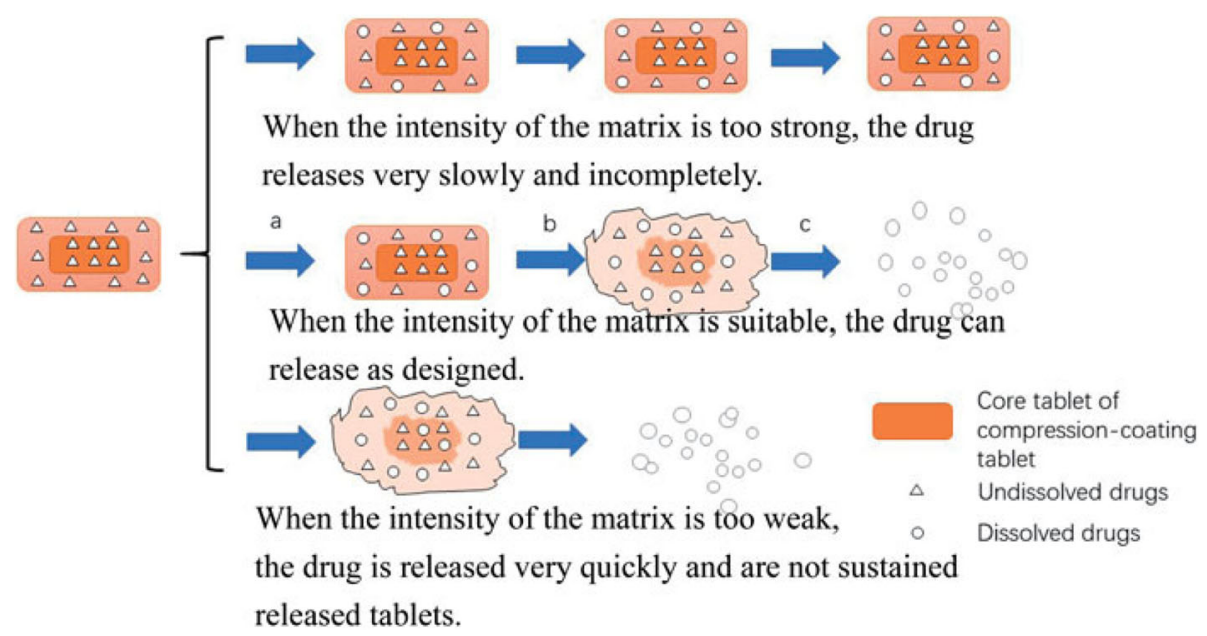

Fig. 3 Possible scheme for drug release from compression coating tablets [6]

$$
\begin{aligned}
& \operatorname{RM}(\%)=\frac{W_{r}}{W_{0}} \times 100 \\
& \operatorname{SR}(\%)=\frac{W_{t}-W_{r}}{W_{r}} \times 100
\end{aligned}
$$

where $W_{O}$ is the initial weight of the dry tablet; $W_{r}$ is the weight of remaining dried tablet after entering the media at time $t ; W_{t}$ is the weight of the tablet without water on the surface at time $t$.

\section{Conclusion}

Film and sugar coatings are an important part of the formulation of the tablet to achieve superior appealing quality like color, texture, mouth feel, and taste masking. Film and sugar coatings have several disadvantages; the most important one is the utilization of aqueous or organic solvent leads to toxicity. The Tablet in Tablet technique is the best alternative to overcome the abovementioned problem. The development of a modified release system of similar drug or different drugs of a different category, or to achieve the drug release at different site absorption can make possible by Tablet in Tablet technique.

\section{Abbreviations}

Fig: Figure; FU: Fluorouracil; hrs: Hour; OSDrC ${ }^{\circledR}$ : One-step dry-coating; RM: Remaining mass; rpm: Revolution per minute; SR: Swelling ratio; TP: Thymidine phosphorylase; US: United States; UV: Ultra violet

\section{Acknowledgments}

The authors are grateful to the management of MET's Institute of Pharmacy, Bhujbal Knowledge City, Adgaon, Nashik-422003 affiliated to Savitribai Phule Pune University, India, for providing necessary facilities to carry out this work.

\section{Authors' information}

SSG is the first author contributing in collection of information and writing of manuscript. SJK is second author contributing in grammatically molding and writing of manuscript and gives their scientific suggestion.

\section{Funding}

Not available any type of funding for this review.

Availability of data and materials

Data will not be shared because of its review article, so there is no practical data available apart from the manuscript and their references.

Ethics approval and consent to participate

Not applicable.

\section{Consent for publication}

Not applicable.

\section{Competing interests}

The authors declare that they have no competing interests.

Received: 27 June 2019 Accepted: 26 November 2019

Published online: 02 January 2020

\section{References}

1. Abebea A, Akselib I, Sprockela O, Kottalaa N, Cuiti AM (2014) Review of bilayer tablet technology. Int. J. Pharm 461:549-558

2. Bose S, Bogner RH (2007) Solventless pharmaceutical coating processes: a review. Pharm Dev Technol 12:115-131

3. Gaikwad SS, Jadhav AA, Chavan MK, Salunkhe KS, Ramteke KH, Chaudhari SR (2016) Design and in vitro evaluations of sublingual tablet of timolol maleate. Applied Clinical Research, Clinical Trials \& Regulatory Affairs 3:56-63

4. Hariharan M, Gupta VK (2002) A novel concept for the production of compression-coated tablets. Pharm. Technol. Eur. 14(4):46-56

5. Huang H, Wu Z, Qi A, Zhang H, Chen Q (2013) Compression-coated tablets of glipizide using hydroxypropylcellulose for zero-order release: In vitro and in vivo evaluation. Int. J. Pharm 446:211-218

6. Liu T, Shi Y, Li J, Jiang W, Yin T et al (2018) Nifedipine di-matrix depot tablets prepared by compression coating for obtaining zero-order release. Drug Dev Ind Pharm doi. https://doi.org/10.1080/03639045.2018.1458859

7. Maiti S (2014) OSDrC ${ }^{\oplus}$ : a revolution in drug formulation technology. Journal of PharmaSciTech 4(1):12-13

8. Maity S, Sa B (2016) Compression-coated tablet for colon targeting: impact of coating and core materials on drug release. AAPS PharmSciTech 17(2): 504-515 
9. Mannan A, Rao KP (2015) Novel chewable Tablet in Tablet dosage form of Orlistat and Venlafaxine hydrochloride: development and evaluation. Journal of Applied Pharmaceutical Science 5(03):91-97

10. Ozeki Y, Watanabe Y, Inoue S, Danjo K (2003) Evaluation of the compression characteristics and physical properties of the newly invented one-step drycoated tablets. Int. J. Pharm 267:69-78

11. Ozekia Y, Andoa M, Watanabea Y, Danjob K (2004) Evaluation of novel onestep dry-coated tablets as a platform for delayed-release tablets. J Control Release 95:51-60

12. Patel P (2019) Bodakdev Ahmedabad. US Patent 20190142755, 16 May 2019.

13. Pawar R, Jaimini M, Chauhan BS, Sharma SK (2014) Compression coated tablets as drug delivery system (tablet in tablet): a review. International Journal of Pharmaceutical Research and Development 6(1):21-33

14. Shah R, Patel S, Patel H, Pandey S, Shah S (2011) Formulation development of Carvedilol compression coated tablet. Pharm Dev Technol 1-10.

15. Tang $Y$, Teng H, Shi Y, He H, Zhang Y et al (2018) Tablets of paliperidone using compression-coated technology for controlled ascending release. A J Pharma Sci 13:143-154

16. United State pharmacopeia 32/NF27, The official compendia of standards, Asian Edition. United States pharmacopeial convection Inc., Rockville MD 2009.

17. Wardrop J, Jaber AB, James W, Ayres JW (1998) Multiple-layer compressioncoated tablets: formulation and humidity studies of novel chewable amoxicillin/clavulanate tablet formulations. Drug Dev Ind Pharm 24(8):729-736

18. Lin K-H, Lin S-Y, Li M-J (2001) Compression forces and amount of outer coating layer affecting the time-controlled disintegration of the compression-coated tablets prepared by direct compression with micronized ethylcellulose. Journal of Pharmaceutical Sciences 90(12):20052009

\section{Publisher's Note}

Springer Nature remains neutral with regard to jurisdictional claims in published maps and institutional affiliations.

\section{Submit your manuscript to a SpringerOpen ${ }^{\circ}$ journal and benefit from:}

- Convenient online submission

- Rigorous peer review

- Open access: articles freely available online

High visibility within the field

- Retaining the copyright to your article

Submit your next manuscript at $\boldsymbol{\nabla}$ springeropen.com 